\title{
ARTICLE Exogenous abscisic acid significantly affects proteome in tea plant (Camellia sinensis) exposed to drought stress
}

\author{
Lin Zhou ${ }^{1}$, Hui Xu ${ }^{1}$, Sue Mischke ${ }^{2}$, Lyndel W Meinhardt ${ }^{2}$, Dapeng Zhang ${ }^{2}$, Xujun Zhu ${ }^{1}$, Xinghui Li ${ }^{1}$ and Wanping Fang ${ }^{1,2}$
}

Tea [Camellia sinensis (L.) O. Kuntze] is an important economic crop, and drought is the most important abiotic stress affecting yield and quality. Abscisic acid (ABA) is an important phytohormone responsible for activating drought resistance. Increased understanding of $A B A$ effects on tea plant under drought stress is essential to develop drought-tolerant tea genotypes, along with crop management practices that can mitigate drought stress. The objective of the present investigation is evaluation of effects of exogenous ABA on the leaf proteome in tea plant exposed to drought stress. Leaf protein patterns of tea plants under simulated drought stress [(polyethylene glycol (PEG)-treated] and exogenous ABA treatment were analyzed in a time-course experiment using two-dimensional electrophoresis (2-DE), followed by matrix-assisted laser desorption/ionization time-of-flight (MALDI-TOF) mass spectrometry (MS). Among the 72 protein spots identified by MALDI-TOF MS, 16 proteins were downregulated and two were upregulated by exogenous ABA. The upregulated proteins have roles in glycolysis and photosystem II stabilization. Twenty-one protein spots were responsive to drought stress and most participate in carbohydrate and nitrogen metabolism, control of reactive oxygen species (ROS), defense, signaling or nucleic acid metabolism. The combined treatments of exogenous ABA and drought showed upregulation of 10 protein spots at $12 \mathrm{~h}$ and upregulation of 11 proteins at $72 \mathrm{~h}$ after initiation of drought stress. The results support the importance of the role that ABA plays in the tea plant during drought stress, by improving protein transport, carbon metabolism and expression of resistance proteins.

Horticulture Research (2014) 1, 14029; doi:10.1038/hortres.2014.29; published online: 25 June 2014

\section{INTRODUCTION}

Tea [Camellia sinensis L.) Kuntze] is a shrub native to China, but cultivated as an important economic crop in more than 50 countries around the world, with an annual production of 4.8 million tons (FAOSTAT, 2012). The top five tea producers are China, India, Sri Lanka, Kenya and Turkey, which collectively share $75 \%$ of world production (FAOSTAT, 2012). The crop is typically cultivated in a rain-fed agricultural system, and tea plants are severely affected by various abiotic stresses such as drought, salinity, temperature, heavy metals and soil nutrient deficiency. ${ }^{1}$ Among these, drought is a major stress that causes severe damage on the yield and quality of tea products. ${ }^{1}$ In recent years, drought-caused damage has become increasingly more frequent and unpredictable due to global climate changes and growing water scarcity. ${ }^{2,3}$

Understanding drought-induced responses of tea plants is an essential first step for breeding tea varieties with increased drought resistance and for developing crop management practices that can mitigate drought stress. Drought-induced responses have been observed at the levels of morphological, physiological or molecular changes at different stages of tea plant development. ${ }^{1}$ Physiological effects of drought stress in tea were increases in proline content, $\mathrm{H}_{2} \mathrm{O}_{2}$ and superoxide anion, lipid peroxidation, activities of catalase and superoxide dismutase and in water loss rate; and decreases in relative water content, dry mass, chlorophyll, carotenoid, total phenolic contents of leaf and antioxidants such as ascorbate and glutathione. ${ }^{1,4}$ Damayanthi ${ }^{5}$ showed that drought-tolerant tea cultivars maintained a high water status, with a substantial rate of photosynthesis, as a result of osmotic adjustments, elevated total soluble sugars and deep rooting. Droughtinduced responses at the gene level have also been investigated in tea plants. Using suppression subtractive hybridization, Gupta ${ }^{6}$ identified a set of drought-responsive genes under controlled conditions, and validated the identified genes and their patterns of expression under drought conditions in the field. Das ${ }^{7}$ identified differentially expressed genes in roots of tea under drought stress by analyzing a suppression subtractive hybridization CDNA library.

Abscisic acid (ABA) is a plant hormone that functions as an endogenous messenger in response to biotic and abiotic stresses. ${ }^{8-11} A$ well-known response to drought stress is the biosynthesis of $A B A$, which is the signal that triggers a number of molecular and cellular responses, ultimately resulting in stomatal closure. The mechanism involves ABA's stimulation of second messengers such as reactive oxygen species (ROS), nitric oxide and $\mathrm{Ca}^{2+}$, followed by activation and inactivation of protein kinases/phosphatases that target the ion channels to prevent water loss. ${ }^{12}$ Previous studies indicated that exogenous $A B A$ treatment can induce drought resistance in tomato, ${ }^{13}$ spring wheat ${ }^{14}$ and Populus. ${ }^{15}$ Increase in ABA levels after exposure to drought has been reported in Arabidopsis thaliana, ${ }^{16,17}$ rice $^{18}$ and tomato, ${ }^{19}$ and an ABA-mimicking ligand that reduces water loss and promotes drought resistance was recently reported in plants. ${ }^{20}$ Therefore, ABA production has attracted much research attention as a potentially useful trait in selecting for drought tolerance in crops. However, direct application of ABA in actual agriculture was considered impractical, due to the concern of costeffectiveness.

The analysis of the plant proteome is a powerful approach to evaluate drought-responsive proteins. ${ }^{21}$ Proteomic investigation has been conducted in several tree species such as holm oak, peach, peanut, poplar, rubber tree, white spruce and maritime pine. ${ }^{22}$ Twodimensional electrophoresis $(2-D E)^{23}$ has been one of the most

${ }^{1}$ College of Horticulture, Nanjing Agricultural University, Nanjing 210095, China and ${ }^{2}$ USDA/ARS, Beltsville Agricultural Research Center, SPCL, Beltsville, MD 20705, USA.

Correspondence: WP Fang (fangwp@njau.edu.cn)

Received: 3 April 2014; Revised: 21 April 2014; Accepted: 30 April 2014 
prevalent techniques for analyzing complex protein mixtures and assessing drought-induced responses in different plant species. ${ }^{24-29}$ Using 2-DE technique, Guo et al. ${ }^{30}$ conducted a proteomic analysis to elucidate alterations of protein expression in response to drought in leaves of tea plants. Significant protein changes were found in tea leaves under polyethylene glycol (PEG)-induced stress. The identified proteins have important roles in various physiological processes that are directly or indirectly associated with tea plant's response to stresses.

Despite various reports on the induced physiological and biochemical responses of tea plant, recently reviewed by Upadhyaya and Panda, ${ }^{1}$ there is still a large gap in knowledge gap about underlying molecular mechanisms of drought adaptation in tea. Thus far, there have been no proteomic studies addressing the effect of exogenous $A B A$ on tea plant exposed to drought stress. Moreover, it is known that, in other plant species, different drought tolerance and avoidance strategies require different metabolic adaptations. $^{21}$

In the present study, we analyzed drought and ABA-responsive proteins in tea plant by using 2-DE and matrix-assisted laser desorption/ionization time-of-flight (MALDI-TOF) mass spectrometry (MS). Our objective was to evaluate the effects of exogenous ABA on leaf proteome when the plant was exposed to drought stress. Leaf protein patterns of tea plants under simulated drought stress (PEG-treated) and exogenous ABA treatment were analyzed using 2-DE followed by MALDI-TOF MS. This study will contribute to an improved understanding of the molecular basis of drought tolerance in tea plant.

\section{MATERIALS AND METHODS}

\section{Plant material and stress treatments}

Tea plant cultivar, 'Ying Shuang' (C. sinensis cv. Yingshuang) is an improved cultivar bred by the Tea Research Institute, Chinese Academy of Agricultural Sciences. The two-year-old plants were grown in greenhouse $(3000 \mathrm{~lx}, 16 \mathrm{~h}$ light $/ 8 \mathrm{~h}$ dark) at temperature ranging from $15{ }^{\circ} \mathrm{C}$ to $20^{\circ} \mathrm{C}$. The humidity index was set for $60 \%-70 \%$ (College of Horticulture, Nanjing Agricultural University, Nanjing, China). Tea plants were cultured, in groups of 20, in $20 \mathrm{~L}$ polyethylene basins with $15 \mathrm{~L} \mathrm{pH} 5.5$ nutrient solution (formula provided by Institute of Soil Science, Chinese Academy of Sciences, Nanjing, China). ${ }^{31}$ The nutrient solution was aerated daily at 8:00-10:00 a.m., 12:00-14:00 p.m. and 16:00-18:00 p.m.

Tea plants were sprayed with $250 \mathrm{~mL}$ of ABA solution, concentration $50 \mathrm{mg} \mathrm{L}^{-1}$, while controls were sprayed with distilled water. After 3 days, $10 \%$ PEG-6000) was used to simulate drought stress. Each treatment had three replicates. During the period of drought stress, treated leaves were sampled at $0 \mathrm{~h}, 12 \mathrm{~h}$ and $72 \mathrm{~h}$ after the application of PEG-6000, frozen immediately in liquid $\mathrm{N}_{2}$ and stored at $-70{ }^{\circ} \mathrm{C}$.

Determination of chlorophyll, free proline and malondialdehyde content

Leaf chlorophyll was extracted with ethanol according to Knudson et al. ${ }^{32}$ The concentration of free proline in tea leaves was determined by using the acid-ninhydrin method developed by Bates et al. ${ }^{33}$ The content of malondialdehyde (MDA) in the leaves was measured by the thiobarbituric acid method, according to Dhindsa et al..$^{34}$ All experiments were carried out with at least three independent repetitions. All statistical analyses were performed with SPSS 20.0 (Windows; SPSS Inc., Chicago, IL, USA) and significance tests were determined by Duncan's test and ANOVA.

\section{Preparation of total protein extracts and 2-DE}

Soluble protein was extracted from $1.0 \mathrm{~g}$ of each sample by homogenization in liquid $\mathrm{N}_{2}$ in a mortar, followed by extraction with TCA/acetone precipitation as described by Jacobs et al. ${ }^{35}$ The air-dried pellet $(700 \mathrm{mg})$ was resuspended in $700 \mu \mathrm{L}$ lysis buffer (7 M urea, $2 \mathrm{M}$ thiourea, 4\% CHAPS, $0.2 \%(\mathrm{w} / \mathrm{v})$ Bio-Lyte, $65 \mathrm{mM}$ dithiothreitol, or DTT) and vortexed for $1 \mathrm{~h}$ at $25{ }^{\circ} \mathrm{C}$. After centrifugation (14000 r.p.m., $30 \mathrm{~min}$ at $4{ }^{\circ} \mathrm{C}$ ), the supernatant was isolated. The supernatant was cleared by centrifugation again (14000 r.p.m., $30 \mathrm{~min}$ at $4{ }^{\circ} \mathrm{C}$ ), and further analysis was performed on the total soluble protein extract in the final supernatant. Protein concentrations were measured with bovine serum albumin as a standard, according to the Coomassie Brilliant Blue G-250 method. ${ }^{36}$

Isoelectric focusing (IEF) to separate proteins based on their isoelectric point (pl) was performed in a PROTEAN IEF System (Bio-Rad, Hercules, CA, USA) using $17 \mathrm{~cm} \mathrm{pH} \mathrm{4-7} \mathrm{immobilized} \mathrm{protein} \mathrm{gradient} \mathrm{strips} \mathrm{(Bio-Rad).}$ Strips were rehydrated by loading samples of $2.2 \mathrm{mg}$ protein dissolved in $500 \mu \mathrm{L}$ rehydration buffer into the channels of the IEF tray and actively rehydrating at $20{ }^{\circ} \mathrm{C}$ for $12 \mathrm{~h}$. Focusing was performed at $20{ }^{\circ} \mathrm{C}, 60 \mathrm{kVh}$ with a maximum current setting of $50 \mu \mathrm{A}$ strip $^{-1}$. After IEF, the immobilized protein gradient strips were equilibrated for $15 \mathrm{~min}$ in $6 \mathrm{M}$ urea, $20 \%$ glycerol, $2 \%$ sodium dodecyl sulfate in $0.375 \mathrm{M}$ Tris- $\mathrm{HCl} \mathrm{pH} 8.8$, containing $2 \%$ $(\mathrm{w} / \mathrm{v})$ DTT for the first equilibration step and $2.5 \%(\mathrm{w} / \mathrm{v})$ iodoacetamide for the second. For the second dimension sodium dodecyl sulfate-polyacrylamide gel electrophoresis, a Protean II Multi Cell (Bio-Rad) was used to separate the proteins by their size. The strips were placed on top of $13.5 \%(\mathrm{w} / \mathrm{v})$ polyacrylamide gels and electrophoresis was performed at $1 \mathrm{~mA} \mathrm{gel}^{-1}$ for $40 \mathrm{~min}$, followed by $15 \mathrm{~mA} \mathrm{gel}^{-1}$ for $4 \mathrm{~h}$. After electrophoresis, gels were stained with a modified Coomassie Brilliant Blue staining method. ${ }^{37}$ Stained gels were scanned by the Versadoc 3000 Imaging System (Bio-Rad). Images were analyzed by using the PDQuest 2-D software (version 8.0.1; Bio-Rad), and several key parameters, such as smooth and saliency, were fixed as constants in the image analysis to obtain comparable data for the quantitative analysis. Spots that showed consistent positions on different gels were considered to be the same proteins. Only those spots whose quantity was changed more than twofold in each of three replicated experiments were collected and sent to Shanghai Boyuan Biological Technology Co. (Shanghai, China) for MS analysis.

\section{MS and database searching}

Differentially expressed proteins were destained and digested by using the improved in-gel digestion method developed by Katayama et al. ${ }^{38}$ The excised spots were analyzed using an ABI 4800 MALDI-TOF/TOF Plus mass spectrometer (Applied Biosystems, Foster City, CA, USA). Mass spectra $(\mathrm{m} / \mathrm{z}$ range: $800-3500 \mathrm{Da}$ ) were processed and the parameters of peak detection algorithm were used. Our MS data were searched against the National Center Biotechnology Information (NCBI) protein sequence database by an in-house MASCOT (version 2.1; Matrix Science, London, UK) search engine. The search parameters were as follows: one missed cleavage allowed, alkylation of cysteine by carbamidomethylation as a fixed modification and oxidation of methionine as a variable modification. Other search parameters were $\pm 0.15 \mathrm{Da}$ for peptide mass tolerance, $\pm 0.25 \mathrm{Da}$ for fragment mass tolerance and number of queries set as 95 . To get more information regarding these proteins, the conserved domains were predicted with BLAST against the NCBI non-redundant database (http://www.ncbi.nlm.nih.gov/blast/Blast.cgi). The similarity of the proteins was also analyzed by BLAST (http://www. expasy.org/cgi-bin/blast.pl). The NCBI Reference Sequence (RefSeq) database (http://www.ncbi.nlm.nih.gov/RefSeq/) provides a non-redundant collection of sequences representing genomic data, transcripts and proteins. However there is little proteomic information available on Camellia sinensis. In order to get the functional information about these proteins, their homologs were searched with BLASTP (http://www.expasy.org/tools/blast/) by using their protein sequences as queries.

\section{RESULTS}

Responsive change of chlorophyll, proline and MDA under drought stress and ABA treatment

The chlorophyll, proline and MDA content remained unchanged in response to exogenous $A B A$ pre-treatment when measured at $0 \mathrm{~h}$ of drought treatment (Figure 1). The drought stress significantly decreased the leaf chlorophyll content (Figure 1a), but treatment with exogenous $A B A$ significantly ameliorated the effects of drought stress on chlorophyll. Proline and MDA content both showed significant increases under drought stress (Figure1b and 1c). The drought-induced increase in MDA content was significantly repressed by exogenous $A B A$ treatment, similarly to chlorophyll. However, a dramatic further increase in proline content was observed with exogenous ABA treatment of tea plants.

Identification of protein spots related to exogenous ABA treatment In order to identify the differential expression of proteins under treatment with exogenous $A B A$, proteins extracted from leaves 

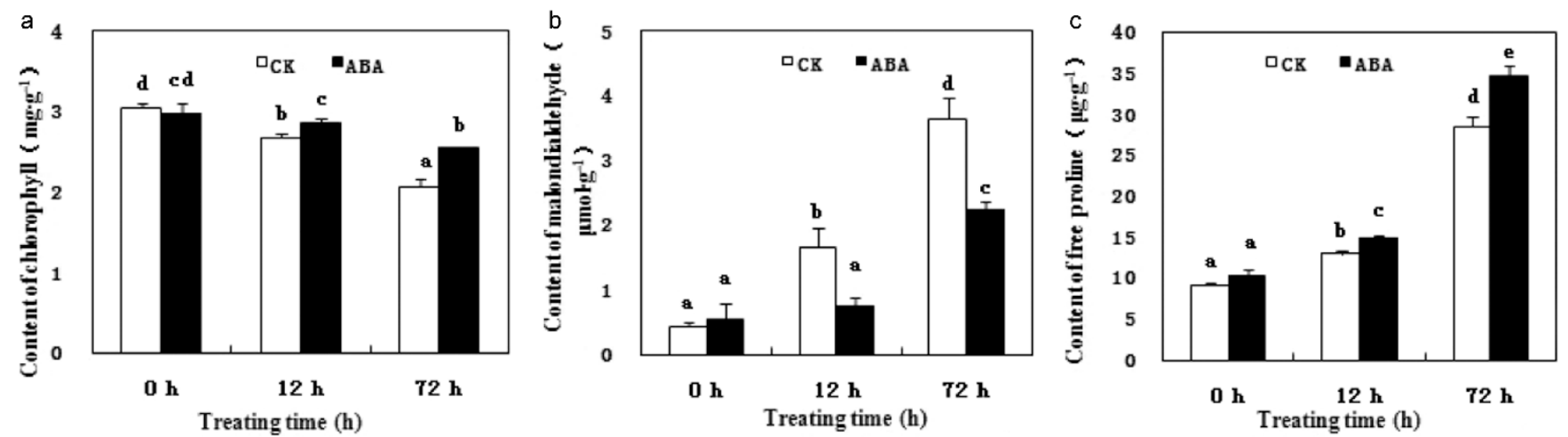

Figure 1. Effects of drought on chlorophyll, proline and MDA content of tea plant. ABA: pre-treated with abscisic acid; CK: control, pre-treated with distilled water.

were separated by 2-DE. More than 700 protein spots were reproducibly detected in each Coomassie Brilliant Blue-stained gel, which included those with molecular weight ranging from 11.0 to $100.0 \mathrm{kDa}$ and $\mathrm{pl}$ ranging from 4.55 to 6.85 . Eighteen specific proteins (detected in three independent biological replicates on each 2-DE gel) were expressed under ABA treatment (Figure 2). The 18 protein spots were identified by MALTI-TOF analysis and NCBI database search, and 16 of the spots were matched to known proteins, while 2 spots were unnamed proteins without specific functions defined in the NCBI database (Table 1). The identified proteins were involved in photosynthesis (spots 4, 9, 11, 12, 14, 15 and 16); carbon metabolism (spot 1); nitrogen metabolism (spots 6 and 7); lipid metabolism (spot 10); heat-shock (spot 8); energy metabolism (spots 2 and 3); and DNA repair (spot 13). Among the 18 proteins related to ABA treatment, spot 1 (2,3-bisphosphoglycerate-independent phosphoglycerate mutase, iPGAM) and spot 12 (oxygen-evolving enhancer protein 1, chloroplastic, i.e., OEE1) were both significantly increased, while the remaining spots were all significantly decreased. Spots 11 and 12 were OEEs. We found that exogenous ABA upregulated OEE (spot 12) 16-fold, even though spot 11 was decreased.

Identification of drought-responsive protein spots

The proteome of tea plant leaves in response to drought stress was resolved by $2-D E$, using triplicate gels. Representative gels are illustrated in Figure 3, and the global pattern of proteins remained largely unaltered. However, the expression levels of 21 proteins were changed at least 2.0-fold in one or both of the drought treatment stages (Figure 4). Besides the unknown and predicted proteins (spots 14, 18, 19, 20 and 21), other identified proteins were classified into several functional categories including regulatory proteins, energy-related proteins, redox homeostasis-related proteins, etc. (Table 2). The largest functional protein was involved in carbohydrate metabolic processes and nitrogen metabolic processes, which were greatly affected by drought stress. Comparison of the identified proteins between drought-affected and control samples showed all spots except 12, 20 and 21 were significantly downregulated in tea plant for the $12 \mathrm{~h}$ samples (Figure 4). Compared with the controls, five protein spots (spots 9, 12, 17, 18 and 19) were upregulated, and 16 spots (spots $1-8,10,11,13-16,20$ and 21) were downregulated (Figure 4). Spots 2 and 20 were present in abundance in the control leaves, but undetected in PEG-treated leaves at $72 \mathrm{~h}$, suggesting that PEG-induced alterations of membrane proteins in tea plant leaves included both quantitative (increased or decreased) and qualitative changes in protein spots. One of inevitable consequences of water stress is that ROS accumulation is enhanced and distributed in different cellular compartments, e.g., chloroplasts, the peroxisomes and the mitochondria. Treatment with $10 \%$ PEG-6000 for $12 \mathrm{~h}$ and $72 \mathrm{~h}$, damaged the photosynthetic and antioxidant enzyme systems of tea plants.
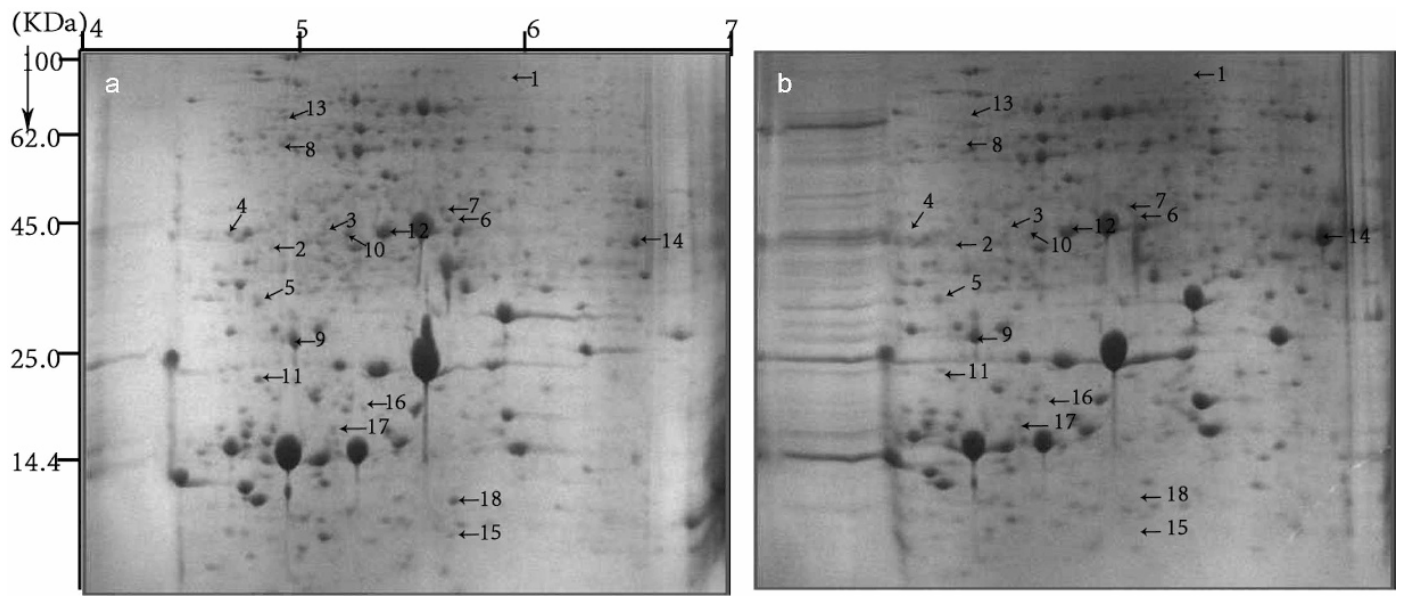

Figure 2. A 2-DE analysis of tea leaf proteins. (a) 2-DE gels of tea leaf subjected to distilled water (control); (b) 2-DE gels of tea leaf subjected to $50 \mathrm{mg} \mathrm{L}^{-1} \mathrm{ABA}$. This is a representative figure from three biological replicas. 
Table 1. The identification of differentially expressed proteins in tea leaves subjected to exogenous ABA pre-treatment

\begin{tabular}{|c|c|c|c|c|c|c|c|c|c|c|}
\hline \multirow[b]{2}{*}{ Spot no. } & \multirow[b]{2}{*}{ Protein name } & \multirow[b]{2}{*}{ Accession no. ${ }^{a}$} & \multirow[b]{2}{*}{ Species } & \multicolumn{2}{|c|}{ Theoretical } & \multicolumn{2}{|c|}{ Experimental } & \multirow[b]{2}{*}{ Score ${ }^{b}$} & \multirow{2}{*}{\multicolumn{2}{|c|}{$\begin{array}{l}\% \operatorname{cov}(\text { matching } \\
\text { peptides) })^{c}\end{array}$}} \\
\hline & & & & $M_{\mathrm{r}}(\mathrm{kDa})$ & $\mathrm{pl}$ & $M_{\mathrm{r}}(\mathrm{kDa})$ & $\mathrm{pl}$ & & & \\
\hline 1 & $\begin{array}{l}\text { 2,3-bisphosphoglycerate-independent } \\
\text { phosphoglycerate mutase }\end{array}$ & Q42908 & $\begin{array}{l}\text { Mesembryanthemum } \\
\text { crystallinum }\end{array}$ & 61.32 & 5.39 & 85.45 & 6.19 & 142 & $8 \%(3)$ & +3.28 \\
\hline 2 & ATP synthase CF1 alpha subunit & YP_538920 & Gossypium hirsutum & 55.44 & 5.25 & 44.32 & 5.41 & 544 & $17 \%(6)$ & -4.34 \\
\hline 3 & ATP synthase CF1 alpha subunit & YP_053140 & Nymphaea alba & 55.54 & 5.58 & 59.38 & 5.59 & 351 & $13 \%(5)$ & -3.57 \\
\hline 4 & $\begin{array}{l}\text { Chloroplast ribulose } 1,5 \text {-bisphosphate } \\
\text { carboxylase/oxygenase activase }\end{array}$ & ABW80752 & Flaveria bidentis & 48.81 & 6.10 & 40.90 & 5.20 & 465 & $15 \%(5)$ & -4.01 \\
\hline 5 & $\begin{array}{l}\text { FE861219.1 EST0078 Tender roots } \\
\text { cDNA library of tea plant Camellia } \\
\text { sinensis cDNA clone 07102311- } \\
\text { CHAG_17_03.M13+_C01.ab1, } \\
\text { mRNA sequence }\end{array}$ & FE861219 & Camellia sinensis & 31.02 & 5.54 & 36.35 & 5.25 & 143 & $14 \%(3)$ & -8.19 \\
\hline 6 & Glutamine synthetase & BAD99525 & Camellia sinensis & 39.40 & 5.79 & 44.52 & 6.00 & 367 & $26 \%(4)$ & -2.79 \\
\hline 7 & Glutamine synthetase, chloroplastic & 022506 & Daucus carota & 48.08 & 5.63 & 45.56 & 5.97 & 142 & $14 \%(3)$ & -4.01 \\
\hline 8 & High molecular weight heat shock protein & AAF34134 & Malus $\times$ domestica & 71.57 & 5.17 & 60.23 & 5.42 & 454 & $11 \%(3)$ & -2.14 \\
\hline 9 & Light-harvesting complex I protein (Lhca1) & XP_002315298 & Populus trichocarpa & 26.53 & 6.10 & 28.12 & 5.40 & 323 & $13 \%(2)$ & -9.07 \\
\hline 10 & Lipoxygenase & ACJ54281 & Camellia sinensis & 102.59 & 6.39 & 49.36 & 5.67 & 91 & $4 \%(3)$ & -4.37 \\
\hline 11 & Oxygen-evolving enhancer protein & AEN02470 & Camellia sinensis & 35.54 & 8.13 & 21.16 & 5.30 & 225 & $20 \%(2)$ & -2.02 \\
\hline 12 & $\begin{array}{l}\text { Oxygen-evolving enhancer protein } 1 \text {, } \\
\text { chloroplastic }\end{array}$ & P26320 & Solanum tuberosum & 35.60 & 5.84 & 37.16 & 5.83 & 340 & $21 \%(4)$ & +16.07 \\
\hline 13 & $\begin{array}{l}\text { Predicted: putative DNA repair protein } \\
\text { RAD23-3 }\end{array}$ & XP_002282352 & Vitis vinifera & 41.98 & 4.73 & 69.52 & 5.39 & 62 & $10 \%(3)$ & -5.08 \\
\hline 14 & $\begin{array}{l}\text { Ribulose 1,5-biphosphate carboxylase I } \\
\text { arge subunit }\end{array}$ & AAM33278 & Stachys affinis & 50.19 & 6.78 & 37.53 & 6.72 & 399 & $18 \%(5)$ & -50.08 \\
\hline 15 & $\begin{array}{l}\text { Ribulose-1,5-bisphosphate } \\
\text { carboxylase/oxygenase large subunit }\end{array}$ & AAB88833 & Hypecoum imberbe & 50.92 & 6.13 & 11.91 & 6.04 & 73 & $2 \%(1)$ & -2.82 \\
\hline 16 & $\begin{array}{l}\text { Ribulose-1,5-bisphosphate } \\
\text { carboxylase/oxygenase large subunit }\end{array}$ & AAA21212 & Aruncus dioicus & 52.13 & 6.04 & 19.39 & 5.70 & 234 & $15 \%(2)$ & -4.45 \\
\hline 17 & Unnamed protein product & CBI23038 & Vitis vinifera & 25.28 & 6.82 & 22.75 & 5.59 & 117 & $21 \%(3)$ & -4.35 \\
\hline 18 & Unnamed protein product & CAA32182 & Spinacia oleracea & 23.20 & 9.76 & 13.81 & 6.05 & 166 & $19 \%(2)$ & -3.98 \\
\hline
\end{tabular}

${ }^{a}$ Accession number in NCBI database.

${ }^{b}$ Score is a measure of the statistical significance of a match.

${ }^{\mathrm{c}}$ Percentage of predicted protein sequence covered by matched peptides.

Comparison of protein profiles under $A B A$ and drought treatments In order to show the effects of exogenous $A B A$ treatment on these proteins induced by drought stress, the leaf protein pattern in tea plants pre-treated with exogenous ABA was also analyzed using 2$D E$. Thirty-three differentially expressed proteins were selected for categorizing (Table 3). Seven of these proteins (spots 6, 7, 28 and 30-33) were predicted proteins, or unknown or unnamed proteins; 19 were in the Rubisco family; and another seven were proteins responding to PEG stress. The latter proteins included apolipoprotein, chloroplast phosphoribulokinase, cytochrome b6-f complex iron-sulfur subunit 2, fructose-bisphosphate aldolase, high molecular weight heat shock protein (Hsp), S-adenosylmethionine synthase 3 and short-chain dehydrogenase/reductase. These proteins play important roles in many life activities of plant, such as transporter activity, photosynthesis, glycolysis, redox reactions and amino-acid biosynthesis. The expression pattern of these proteins in leaves of tea plant pre-treated with exogenous ABA and single drought treatment (Figure 5) suggests that 23 proteins (spots 1, 2, $4,5,7,9-15,17,19-21,23,25-29$ and 31) were upregulated and 10 spots (spot 3, 6, 8, 16, 18, 22, 24, 30, 32 and 33) were downregulated at $12 \mathrm{~h} ; 11$ proteins (spots 1, 4, 5, 11, 19, 20, 22, 24, 27, 29 and 30) were upregulated at $72 \mathrm{~h}$; and some proteins were downregulated compared with $0 \mathrm{~h}$ (Figures 5 and 6). Apolipoprotein D, chloroplast phosphoribulokinase, fructose-bisphosphate aldolase, high molecular weight Hsp, protein IN2-1 homolog B-like, short-chain dehydrogenase/reductase and most of the Rubisco proteins were upregulated at $12 \mathrm{~h}$ in tea plants that had been pre-treated with ABA.

\section{DISCUSSION}

Because drought stress is one of the major factors limiting the productivity of tea plant in tea-growing countries, knowledge of the mechanism underlying enhanced tolerance to drought stress in tea plant is of importance. To the best of our knowledge, several studies have explored the transcripts in the leaves and roots of tea plants, ${ }^{7,39}$ but few studies examined proteomics of plant leaves in response to the combination of drought stress and exogenous ABA. In this study, we focused on identifying stress proteins induced in tea plant leaf under drought stress combined with exogenous ABA treatment, and we examined changes in several physiological and biochemical characteristics.

$\mathrm{ABA}$ and drought-responsive changes of physiological and biochemical characteristics

Chlorophyll plays an important role in plant photosynthesis, which allows plants to absorb energy from light. Drought stress inhibits the photosynthetic activity in plants by changing chlorophyll content, and a decrease of total chlorophyll content implies lowered light harvesting. ${ }^{40}$ In the present study, the total chlorophyll content was significantly decreased in tea plant under drought stress. Plants can partially protect themselves against biotic and abiotic stresses by accumulating osmolytes. Proline accumulation is one of the most common osmolyte responses to environmental stresses, particularly in plants under drought stress. ${ }^{41}$ Previous studies implied that an increase in proline content (251.64\%) was observed in 1-year-old clonal seedlings of tea after withholding watering for 5 days. ${ }^{4,42}$ In our study, the increase of proline content under drought 

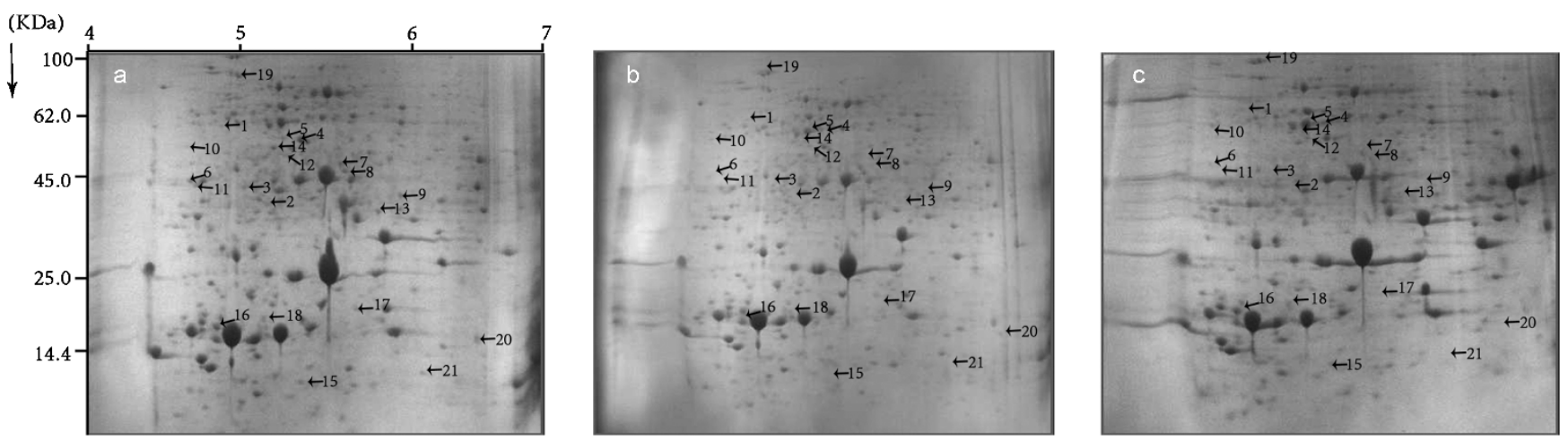

Figure 3. A 2-DE analysis of tea leaf proteins. (a) 2-DE gels of tea leaf subjected to $50 \mathrm{mg} \mathrm{L}^{-1} \mathrm{ABA}$; (b, c) 2-DE gels of tea leaf subjected to drought treatment for $12 \mathrm{~h}$ and $72 \mathrm{~h}$ after pre-treated with $50 \mathrm{mg} \mathrm{L}^{-1} \mathrm{ABA}$. This is a representative figure from three biological replicas.

stress was greater at $72 \mathrm{~h}$ than at $12 \mathrm{~h}$. In many investigations, MDA has been utilized as a suitable biomarker for lipid peroxidation and as an indicator of the extent of ROS damage, thus, the content of MDA is an important indicator of oxidative stress damage. ${ }^{42}$ In this study, drought stress significantly increased the level of MDA, indicating oxidative stress. We found that the contents of chlorophyll and proline in exogenous ABA-pre-treated tea plants were significantly higher than control in response to drought stress. In contrast, higher MDA was observed in control than in ABA treated plants. The variation in chlorophyll, proline and MDA content in this study indicates that exogenous ABA pre-treatment increases the chlorophyll and proline content of the leaf, and reduces membrane lipid peroxidation, thus improves drought tolerance in tea plants pretreated with exogenous $A B A$.

Differentially expressed proteins under $A B A$ and drought treatment Both ABA- and drought-induced changes in protein profile were observed in the present experiment. In plants treated with exogenous ABA, 18 differentially expressed proteins were successfully identified. The present results showed significant $A B A$-induced increase of iPGAM and OEE proteins, which are respectively involved in glycolysis and maintenance of photosystem II stability. ${ }^{43,44}$ ABA pretreatment did not increase expression of the remaining proteins. Thus, exogenous ABA may specifically improve glucose metabolism and advance the stability of the photosystem II stabilization.

The responses of plants to drought stress depend on both the species and the severity of water deficiency. ${ }^{45}$ Moreover, differential expression of drought-responsive protein changes over the length of time plants are subjected to drought stress. The present proteomic study identified numerous drought stress-responsive proteins, such as ascorbate peroxidase, glutamine synthetase, glutathione transferase lambda 2, Hsp 90, the CF1 alpha subunit of ATP synthase and lipoxygenase. Under drought stress, lipoxygenase (Table 2, spot 12) was significantly increased at $12 \mathrm{~h}$, whereas $85.7 \%$ (18/21) proteins were downregulated. The downregulated proteins were involved in the ROS pathway (ascorbate peroxidase), photosynthetic carbon metabolism (chloroplast phosphoribulokinase), nitrogen metabolism (glutamine synthetase), energy metabolism (CF1 alpha subunit of ATP synthase) and photosynthesis (light-induced protein). Treatment with $10 \%$ PEG 6000 might severely affect the carbon and nitrogen metabolism and growth of tea plant, undermining the antioxidant enzyme system. Drought-dependent changes relating to the antioxidant defense system could contribute to decreased chlorophyll and increased MDA. Lipoxygenase (LOX) reactions may initiate synthesis of a signaling molecule, or be involved in inducing structural or metabolic changes in plant cells. ${ }^{46,47}$ Earlier studies reported that drought stress enhanced LOX gene expression and LOX enzyme activity in leaves. ${ }^{48,49}$ In addition, products of LOXs are involved in diverse cell functions.

Comparison of protein profiles under $\mathrm{ABA}$ and drought treatments The experimental design of the present study enabled the identification of ABA-responsive proteins in drought-stressed tea plants, through the comparison of protein profiles under exogenous ABA

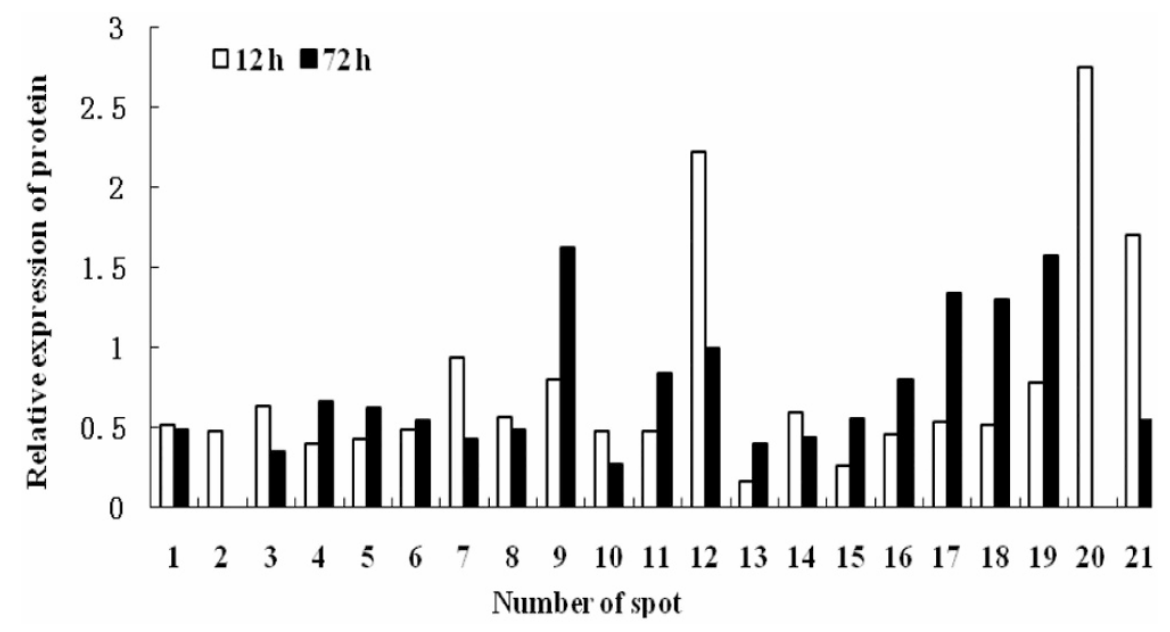

Figure 4. Histograms show the abundance ratio of the identified proteins in tea leaves subjected to drought at $12 \mathrm{~h}$ and $72 \mathrm{~h}$ 
Table 2. The identification of differentially responsive proteins in tea leaves subjected to drought

\begin{tabular}{|c|c|c|c|c|c|c|c|c|c|}
\hline \multirow[b]{2}{*}{ Spot no. } & \multirow[b]{2}{*}{ Protein name } & \multirow[b]{2}{*}{ Accession no. ${ }^{a}$} & \multirow[b]{2}{*}{ Species } & \multicolumn{2}{|c|}{ Theoretical } & \multicolumn{2}{|c|}{ Experimental } & \multirow[b]{2}{*}{ Score $^{b}$} & \multirow{2}{*}{$\begin{array}{l}\% \operatorname{cov}(\text { matching } \\
\text { peptides) })^{c}\end{array}$} \\
\hline & & & & $M_{\mathrm{r}}(\mathrm{kDa})$ & $\mathrm{pl}$ & $M_{\mathrm{r}}(\mathrm{kDa})$ & $\mathrm{pl}$ & & \\
\hline 1 & $39 \mathrm{kDa}$ EF-Hand containing protein & CAA04670 & Solanum tuberosum & 39.01 & 4.65 & 60.13 & 5.34 & 50 & $2 \%(1)$ \\
\hline 2 & Ascorbate peroxidase & ACB45429 & Camellia sinensis & 27.75 & 5.50 & 38.58 & 5.58 & 235 & $37 \%(4)$ \\
\hline 3 & ATP synthase CF1 alpha subunit & NP_862739 & $\begin{array}{l}\text { Calycanthus floridus var. } \\
\text { glaucus }\end{array}$ & 55.21 & 5.20 & 41.46 & 5.50 & 227 & $10 \%(3)$ \\
\hline 4 & Chloroplast phosphoribulokinase & BAL03266 & $\begin{array}{l}\text { Closterium peracerosum- } \\
\text { strigosum-littorale complex }\end{array}$ & 45.77 & 6.28 & 55.02 & 5.76 & 195 & $12 \%(3)$ \\
\hline 5 & Chloroplast phosphoribulokinase & BAL03266 & $\begin{array}{l}\text { Closterium peracerosum- } \\
\text { strigosum-littorale complex }\end{array}$ & 45.77 & 6.28 & 55.65 & 5.67 & 140 & $12 \%(3)$ \\
\hline 6 & $\begin{array}{l}\text { Chloroplast ribulose } 1,5 \text {-bisphosphate } \\
\text { carboxylase/oxygenase activase }\end{array}$ & ABW80752 & Flaveria bidentis & 48.81 & 6.10 & 42.69 & 5.20 & 354 & $17 \%(6)$ \\
\hline 7 & Glutamine synthetase, chloroplastic & 022506 & Daucus carota & 48.08 & 5.63 & 47.88 & 5.97 & 195 & $14 \%(3)$ \\
\hline 8 & Glutamine synthetase & BAD99525 & Camellia sinensis & 39.40 & 5.79 & 45.99 & 5.99 & 361 & $35 \%(5)$ \\
\hline 9 & Glutathione transferase lambda 2 & NP_191064 & Arabidopsis thaliana & 33.15 & 6.78 & 39.26 & 6.29 & 61 & $4 \%(1)$ \\
\hline 10 & Heat shock protein 90 & ACX42226 & Ipomoea nil & 90.65 & 4.92 & 52.91 & 5.19 & 133 & $5 \%(4)$ \\
\hline 11 & Light-induced protein, chloroplastic & P80471 & Solanum tuberosum & 35.67 & 5.26 & 41.21 & 5.22 & 68 & $3 \%(1)$ \\
\hline 12 & Lipoxygenase & ACJ54281 & Camellia sinensis & 102.59 & 6.39 & 49.36 & 5.67 & 91 & $4 \%(3)$ \\
\hline 13 & Os05g0187000 & NP_001054834 & Oryza sativa Japonica Group & 29.26 & 6.45 & 37.22 & 6.18 & 76 & $5 \%(1)$ \\
\hline 14 & $\begin{array}{l}\text { Predicted: sedoheptulose-1,7- } \\
\text { bisphosphatase, chloroplastic }\end{array}$ & XP_002263049 & Vitis vinifera & 42.90 & 5.95 & 52.37 & 5.62 & 427 & $18 \%(5)$ \\
\hline 15 & Thioredoxin X & ACG44176 & Zea mays & 19.25 & 9.20 & 11.65 & 5.75 & 64 & $6 \%(1)$ \\
\hline 16 & $\begin{array}{l}\text { Ribulose-1,5-biphosphate carboxylase/ } \\
\text { oxygenase large subunit }\end{array}$ & ACY64810 & Richea scoparia & 52.11 & 6.08 & 16.66 & 5.29 & 185 & $12 \%(3)$ \\
\hline 17 & Ribulose 1,5-bisphosphate carboxylase & CAQ58398 & $\begin{array}{l}\text { Prismatomeris sp. } 1 \text { Davis } \\
\quad 4057\end{array}$ & 52.12 & 6.34 & 18.53 & 6.06 & 275 & $12 \%(5)$ \\
\hline 18 & Predicted protein & XP_002318440 & Populus trichocarpa & 26.38 & 8.12 & 17.76 & 5.54 & 277 & $19 \%(4)$ \\
\hline 19 & Hypothetical protein VITISV_037064 & CAN69818 & Vitis vinifera & 61.39 & 5.20 & 83.44 & 5.43 & 421 & $11 \%(5)$ \\
\hline 20 & Unknown & ABK92500 & Populus trichocarpa & 80.87 & 6.29 & 15.00 & 6.84 & 45 & $1 \%(1)$ \\
\hline 21 & Unknown & ABK94111 & Populus trichocarpa & 16.59 & 5.14 & 12.60 & 6.45 & 48 & $12 \%(2)$ \\
\hline
\end{tabular}

${ }^{\text {a }}$ Accession number in NCBI database.

${ }^{b}$ Score is a measure of the statistical significance of a match.

${ }^{\mathrm{c}}$ Percentage of predicted protein sequence covered by matched peptides.

and drought treatments. The results demonstrated upregulation of apolipoprotein $\mathrm{D}$, fructose-bisphosphate aldolase, high molecular weight $\mathrm{Hsp}$, short-chain dehydrogenase/reductase and Rubisco expression. Apolipoprotein D plays an important role in lipid transportation. Charron et al. ${ }^{50}$ demonstrated that apolipoprotein D ortholog, AtTIL lipocalin, is involved in modulating tolerance to oxidative stress and provided the first evidence for a functional role of lipocalins in plants. Fructose-bisphosphate aldolase and short-chain dehydrogenase/reductase respectively participate in gluconeogenesis and the Calvin cycle $^{51}$ and in oxidationreduction processes. ${ }^{52}$ The high molecular weight $\left(M_{\mathrm{r}}\right.$ or relative molecular mass) Hsp may be Hsp 70 (theoretical $M_{\mathrm{r}} 71.57 \mathrm{kDa}$, experimental $M_{\mathrm{r}} 60.23 \mathrm{kDa}$ ). Induction of $\mathrm{Hsps}$ is important in allowing cells to cope with acute stress, especially stresses affecting the protein machinery of plant cell. ${ }^{53}$ Previous results showed that ABA-induced $\mathrm{H}_{2} \mathrm{O}_{2}$ production enhances the synthesis of $\mathrm{Hsp} 70$ and upregulates the activities of antioxidant enzymes, resulting in the suppression of cellular ROS levels. ${ }^{54}$ In this study, Hsp70 expression was enhanced by drought in tea plant treated with exogenous $A B A$, which implied that $A B A$ pre-treatment may improve plant tolerance to drought stress by increasing Hsp70 expression.

Rubisco is the major enzyme assimilating $\mathrm{CO}_{2}$ from the atmosphere. ${ }^{55,56}$ Drought stress leads to a rapid decrease in the abundance of Rubisco small-subunit transcripts in tomato, Arabidopsis and rice. ${ }^{57}$ But the short-term responses of Rubisco to drought stress are not clear, as different studies have produced conflicting results. In our study, drought stress leads to increase in the Rubisco large subunit. This information suggests that ABA-pre-treated tea plants may accelerate the rate of photosynthesis through Rubisco, and the elevated photosynthesis increases the level of sugars, whose promoting influence on proline accumulation has been demonstrated in several studies. ${ }^{41}$ Cytochrome b6-f complex iron-sulfur subunit 2, aldehyde dehydrogenase family 2 member B4 and S-adenosylmethionine synthase 3, which participate in photosynthetic reactions, energy metabolism and S-adenosylmethionine biosynthesis, were downregulated under conditions of drought. Taken together, these results suggest that energy production and metabolism were highly disrupted by drought stress. However, the ABA pre-treatment of tea plants improved transportation of the proteins, carbon metabolism and expression of resistance proteins in the absence of drought. Result of the present study is compatible with those found in plants cells for other species. ${ }^{58,59}$ This study also provides a better understanding of molecular mechanism in drought tolerance of tea plant which would be a valuable resource for the further function study of exogenous ABA.

Poor detection of low-abundance proteins is a common problem when using 2-DE for protein separation in a proteome analysis. Most of the 72 identified protein spots were attributed to Rubisco, because Rubisco is the most abundant protein and makes up more than half of the total leaf proteins in some species. ${ }^{60,61}$ In tea leaves, Rubisco accounts for $50 \%$ of soluble leaf protein (20\%-30\% of total leaf nitrogen). Specific proteins that represent a large proportion of the whole-cell proteins are easily detected after separation, whereas low-abundance proteins may be taken up by the immobilized protein gradient strip in only small quantities and hence, are hardly visualized by $2-\mathrm{DE} .^{61,62}$ It is apparent that 


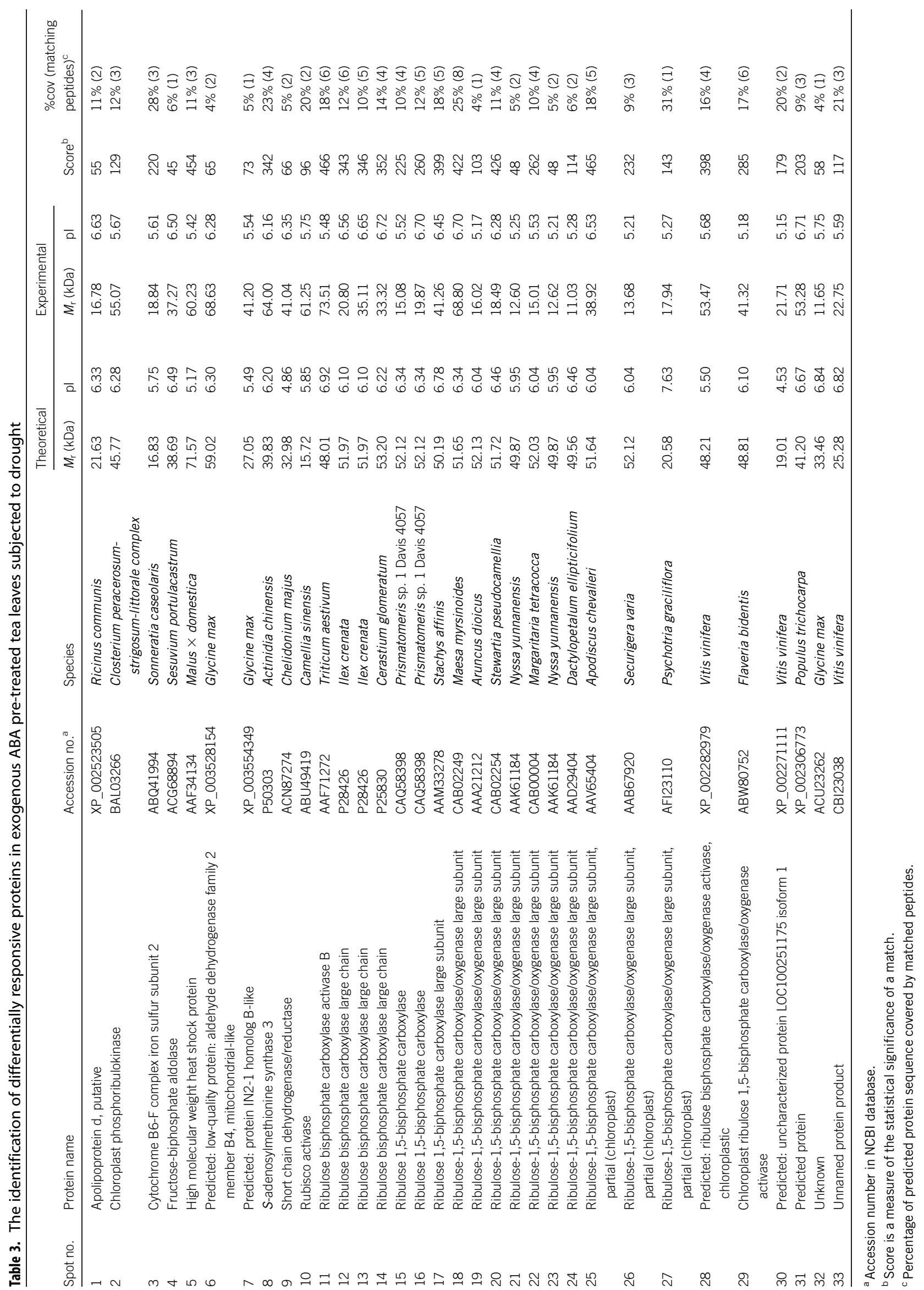



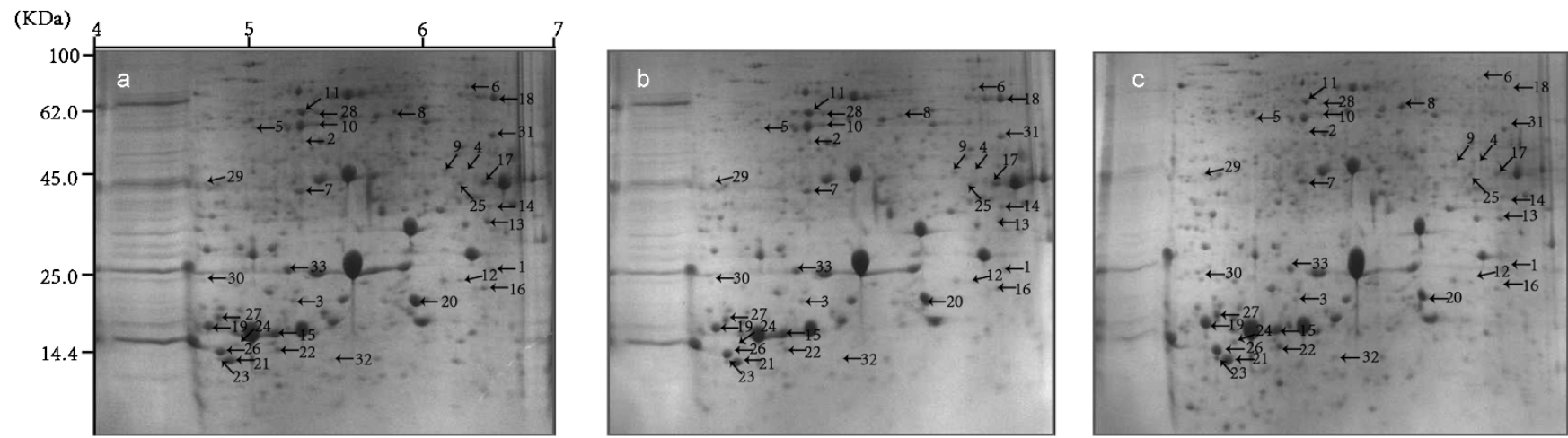

Figure 5. A 2-DE analysis of tea leaf proteins. (a) 2-DE gels of tea leaf subjected to distilled water (control); (b, c) 2-DE gels of tea leaf subjected to drought treatment for $12 \mathrm{~h}$ and $72 \mathrm{~h}$. This is a representative figure from three biological replicas.

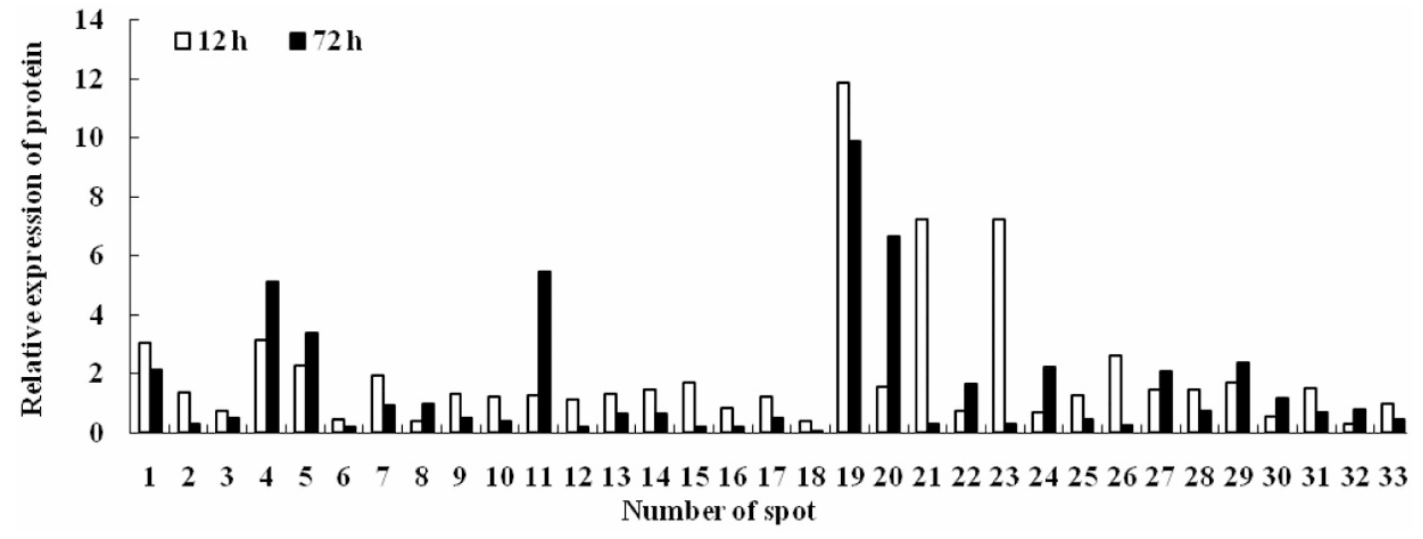

Figure 6. Histograms show the abundance ratio of the identified proteins in exogenous ABA pre-treated tea leaves subjected to drought at $12 \mathrm{~h}$ and $72 \mathrm{~h}$

developing efficient methods to minimize the high-abundance proteins has become an important goal in applications of 2-DE for proteome analysis. One solution is to use root tissue harvested from treated and nontreated plants for proteomic identification, because root tissue does not exhibit an over-representation of highly abundant proteins such as Rubisco found in green tissue. ${ }^{63}$ Roots are also the first sensors of water stress in soil thus would likely provide complementary information in terms of proteins responsive to $A B A$ and drought treatment.

In conclusion, tea has a long legacy in China and its popularity is increasing dramatically throughout the world, making it an important economic crop. Currently, droughts are occurring much more frequently, and in more seasons, and spreading to more regions across the country. Tea production has suffered in both quantity and quality, especially spring tea. In the present study, using comparative proteomics, we identified proteins associated with the drought-stress response and demonstrated $A B A$ regulation of these. This study also demonstrated that ABA pre-treatment was a valuable approach at mitigating drought stress in tea plants under laboratory conditions. This information contributes to the knowledge of the mechanism of resilience to abiotic stress in tea plant, and will be helpful for the further study of the function of exogenous $A B A$ in this species. In future, we hope to extend the findings of this paper to field conditions.

\section{CONFLICT OF INTEREST}

The authors declare no conflict of interest.

\section{ACKNOWLEDGMENTS}

This work was supported by the National Natural Science Foundation of China (30800884, 31370688) and the Jiangsu Science and Technology Program of China (BE2011319).

\section{REFERENCES}

1 Upadhyaya $\mathrm{H}$, Panda SK. Abiotic stress responses in tea [Camellia sinensis $\mathrm{L}(\mathrm{O})$ Kuntze]: an overview. Rev Agric Sci 2013; 1: 1-10.

2 Wijeratne MA, Anandacoomaraswamy A, Amarathunga MK et al. Assessment of impact of climate change on productivity of tea (Camellia sinensis L.) plantations in Sri Lanka. J Natn Sci Found Sri Lanka 2007; 35: 119-126.

3 Pías B, Matesanz S, Herrero A et al. Transgenerational effects of three global change drivers on an endemic Mediterranean plant. Oikos 2010; 119: 1435-1444.

4 Upadhyaya H, Panda SK. Responses of Camellia sinensis to drought and rehydration. Biol Plant 2004; 48: 597-600.

5 Damayanthi MM, Mohotti AJ, Nissanka SP. Comparison of tolerant ability of mature field grown tea (Camellia sinensis L.) cultivars exposed to a drought stress in passara area. Trop Agric Res 2010; 22: 66-75.

6 Gupta S, Bharalee R, Bhorali P et al. Identification of drought tolerant progenies in tea by gene expression analysis. Funct Integr Genomics 2012; 12: 543-563.

7 Das A, Das S, Mondal TK. Identification of differentially expressed gene profiles in young roots of tea [Camellia sinensis (L.) O. Kuntze] subjected to drought stress using suppression subtractive hybridization. Plant Mol Biol Rep 2012; 30: 10881101.

8 Hirayama T, Shinozaki K. Perception and transduction of abscisic acid signals: keys to the function of the versatile plant hormone ABA. Trends Plant Sci 2007; 12: 343351.

9 Ton J, Flors $\mathrm{V}$, Mauch-Mani B. The multifaceted role of ABA in disease resistance. Trends Plant Sci 2009; 14: 310-317. 
10 Zong XJ, Li DP, Gu LK et al. Abscisic acid and hydrogen peroxide induce a novel maize group C MAP kinase gene, $Z m M P K 7$, which is responsible for the removal of reactive oxygen species. Planta 2009; 229: 485-495.

11 Leung J, Giraudat J. Abscisic acid signal transduction. Annu Rev Plant Phys 1998; 49 199-222.

12 Lee SC, Luan S. ABA signal transduction at the crossroad of biotic and abiotic stress responses. Plant Cell Environ 2012; 35: 53-60.

13 Aroca $\mathrm{R}$, Alguacil MD, Vernieri $\mathrm{P}$ et al. Plant responses to drought stress and exogenous $A B A$ application are modulated differently by mycorrhization in tomato and an ABA-deficient mutant (sitiens). Microb Ecol 2008; 56: 704-719.

14 Du YL, Wang ZY, Fan JW et al. Exogenous abscisic acid reduces water loss and improves antioxidant defence, desiccation tolerance and transpiration efficiency in two spring wheat cultivars subjected to a soil water deficit. Funct Plant Biol 2013; 40: 494-506.

15 Li CY, Yin CY, Liu SR. Different responses of two contrasting Populus davidiana populations to exogenous abscisic acid application. Environ Exp Bot 2004; 51 237-246.

16 Christmann A, Weiler EW, Steudle E et al. A hydraulic signal in root-to-shoot signalling of water shortage. Plant J 2007; 52: 167-174.

17 Zeller G, Henz SR, Widmer CK et al. Stress-induced changes in the Arabidopsis thaliana transcriptome analyzed using whole-genome tiling arrays. Plant $J 2009$; 58: $1068-1082$.

18 Rabbani MA, Maruyama K, Abe $\mathrm{H}$ et al. Monitoring expression profiles of rice genes under cold, drought, and high-salinity stresses and abscisic acid application using cDNA microarray and RNA gel-blot analyses. Plant Physiol 2003; 133: 1755-1767.

19 Wallach R, Da-Costa N, Raviv M et al. Development of synchronized, autonomous, and self-regulated oscillations in transpiration rate of a whole tomato plant under water stress. J Exp Bot 2010; 61: 3439-3449.

20 Cao MJ, Liu X, Zhang Y et al. An ABA-mimicking ligand that reduces water loss and promotes drought resistance in plants. Cell Res 2013; 23: 1043-1054.

21 Verslues PE, Juenger TE. Drought, metabolites, and Arabidopsis natural variation: a promising combination for understanding adaptation to water-limited environments. Curr Opin Plant Biol 2011; 14: 240-245.

22 Rossignol M, Peltier JB, Mock HP et al. Plant proteome analysis: a 2004-2006 update. Proteomics 2006; 6: 5529-5548.

23 O'Farrell PH. High resolution two-dimensional electrophoresis of proteins. J Biol Chem 1975; 250: 4007-4021.

24 Kosova K, Vitamvas P, Prasil IT et al. Plant proteome changes under abiotic stresscontribution of proteomics studies to understanding plant stress response. J Proteomics 2011; 74: 1301-1322.

25 Hajheidari M, Abdollahian-Noghabi M, Askari $\mathrm{H}$ et al. Proteome analysis of sugar beet leaves under drought stress. Proteomics 2005; 5: 950-960.

26 Chitteti BR, Peng ZH. Proteome and phosphoproteome differential expression under salinity stress in rice (Oryza sativa) roots. J Proteome Res 2007; 6: 1718-1727.

27 Deeba F, Pandey AK, Ranjan S et al. Physiological and proteomic responses of cotton (Gossypium herbaceum L.) to drought stress. Plant Physiol Bioch 2012; 53: 6-18.

28 Sharmin SA, Alam I, Rahman MA et al. Mapping the leaf proteome of Miscanthus sinensis and its application to the identification of heat-responsive proteins. Planta 2013; 238: 459-474.

29 Shi $Y$, Jiang $L$, Zhang $L$ et al. Dynamic changes in proteins during apple (Malus $X$ domestica) fruit ripening and storage. Horti Res 2014; 1: 6.

30 Guo CF, Sun Y, Lai CC et al. [Proteomic analysis of tea leaf under polyethylene glycol stress.] J Tea Sci 2009; 29: 79-88. Chinese.

31 Wan Q, Xu RK, Li XH. Proton release from tea plant (Camellia sinensis L.) roots induced by $\mathrm{Al}(\mathrm{III})$ under hydroponic conditions. Soil Res 2012; 50: 482-488.

32 Knudson LL, Tibbitts TW, Edwards GE. Measurement of ozone injury by determination of leaf chlorophyll concentration. Plant Physiol 1977; 60: 606-608.

33 Bates LS, Waldren RP, Teare ID. Rapid determination of free proline for water stress studies. Plant Soil 1973; 39: 205-208.

34 Dhindsa RS, Plumb-Dhindsa P, Thorpe TA. Leaf senescence: correlated with increased levels of membrane permeability and lipid peroxidation, and decreased levels of superoxide dismutase and catalase. J Exp Bot 1981; 32: 93.

35 Jacobs DI, Rijssen MS, Heijden R et al. Sequential solubilization of proteins precipitated with trichloroacetic acid in acetone from cultured Catharanthus roseus cells yields $52 \%$ more spots after two-dimensional electrophoresis. Proteomics 2001; 1: 1345-1350.

36 Bradford MM. A rapid and sensitive method for the quantitation of microgram quantities of protein utilizing the principle of protein-dye binding. Anal Biochem 1976; 72: 248-254.

37 Wang XC, Li XF, Li YX. A modified Coomassie Brilliant Blue staining method at nanogram sensitivity compatible with proteomic analysis. Biotechnol Lett 2007; 29: 1599-1603.
38 Katayama $\mathrm{H}$, Nagasu T, Oda Y. Improvement of in-gel digestion protocol for peptide mass fingerprinting by matrix-assisted laser desorption/ionization timeof-flight mass spectrometry. Rapid Commun Mass Sp 2001; 15: 1416-1421.

39 Sharma P, Kumar S. Differential display-mediated identification of three droughtresponsive expressed sequence tags in tea [Camellia sinensis (L.) O. Kuntze]. J Biosci 2005; 30: 231-235.

40 Mafakheri A, Siosemardeh A, Bahramnejad B et al. Effect of drought stress on yield, proline and chlorophyll contents in three chickpea cultivars. Aust J Crop Sci 2010; 4: 580-585.

41 Lehmann S, Funck D, Szabados L et al. Proline metabolism and transport in plant development. Amino Acids 2010; 39: 949-962.

42 Gunes A, Soylemezoglu G, Inal A et al. Antioxidant and stomatal responses of grapevine (Vitis vinifera L.) to boron toxicity. Sci Hort 2006; 110: 279-284.

43 Bricker TM, Roose JL, Zhang PP et al. The PsbP family of proteins. Photosynth Res 2013; 116: 235-250.

44 Mercaldi GF, Pereira HM, Cordeiro AT et al. Structural role of the active-site metal in the conformation of Trypanosoma brucei phosphoglycerate mutase. FEBS J 2012; 279: 2012-2021.

45 Bray EA. Plant responses to water deficit. Trends Plant Sci 1997; 2: 48-54.

46 Brash AR. Lipoxygenases: occurrence, functions, catalysis, and acquisition of substrate. J Biol Chem 1999; 274: 23679-23682.

47 Park YS, Kunze S, Ni XZ et al. Comparative molecular and biochemical characterization of segmentally duplicated 9-lipoxygenase genes ZmLOX4 and ZmLOX5 of maize. Planta 2010; 231: 1425-1437.

48 Bell E, Mullet JE. Lipoxygenase gene-expression is modulated in plants by water deficit, wounding, and methyl jasmonate. Mol Gen Genet 1991; 230: 456-462.

49 Sofo A, Dichio B, Xiloyannis C et al. Lipoxygenase activity and proline accumulation in leaves and roots of olive trees in response to drought stress. Physiol Plantarum 2004; 121: 58-65.

50 Charron JB, Ouellet F, Houde M et al. The plant apolipoprotein D ortholog protects Arabidopsis against oxidative stress. BMC Plant Biol 2008; 8: 86.

51 Teich R, Zauner S, Baurain D et al. Origin and distribution of Calvin cycle fructose and sedoheptulose bisphosphatases in plantae and complex algae: a single secondary origin of complex red plastids and subsequent propagation via tertiary endosymbioses. Protist 2007; 158: 263-276.

52 Moon HJ, Tiwari MK, Singh R et al. Molecular determinants of the cofactor specificity of ribitol dehydrogenase, a short-chain dehydrogenase/reductase. Appl Environ Microb 2012; 78: 3079-3086.

53 Jacques S, Ghesquiere B, van Breusegem $\mathrm{F}$ et al. Plant proteins under oxidative attack. Proteomics 2013; 13: 932-940.

$54 \mathrm{Hu}$ XL, Liu RX, Li YH et al. Heat shock protein 70 regulates the abscisic acid-induced antioxidant response of maize to combined drought and heat stress. Plant Growth Regul 2010; 60: 225-235.

55 Andersson I, Backlund A. Structure and function of Rubisco. Plant Physiol Bioch 2008; 46: 275-291.

56 Raven JA. Rubisco: still the most abundant protein of Earth? New Phytol 2013; 198: 1-3.

57 Parry MAJ, Andralojc PJ, Khan S et al. Rubisco activity: effects of drought stress. Ann Bot-London 2002; 89: 833-839.

58 Liu TX, Zhang L, Yuan ZL et al. Identification of proteins regulated by ABA in response to combined drought and heat stress in maize roots. Acta Physiol Plant 2013; 35: 501-513.

59 Horn R, Chudobova I, Hansel U et al. Simultaneous treatment with tebuconazole and abscisic acid induces drought and salinity stress tolerance in Arabidopsis thaliana by maintaining key plastid protein levels. J Proteome Res 2013; 12: 1266-1281.

60 Ellis RJ. The most abundant protein in the world. Trends Biochem Sci 1979; 4: 241-244.

61 Lee DG, Ahsan N, Lee SH et al. An approach to identify cold-induced low-abundant proteins in rice leaf. CR Biol 2007; 330: 215-225.

$62 \mathrm{Xi} \mathrm{JH}$, Wang X, Li SY et al. Polyethylene glycol fractionation improved detection of low-abundant proteins by two-dimensional electrophoresis analysis of plant proteome. Phytochemistry 2006; 67: 2341-2348.

63 Alvarez S, Choudhury SR, Pandey S. Comparative quantitative proteomics analysis of the $A B A$ response of roots of drought-sensitive and drought-tolerant wheat varieties identifies proteomic signatures of drought adaptability. J Proteome Res 2014; 13: 1688-1701.

(c) (i) $\Theta$ This work is licensed under a Creative Commons Attributioncc) NonCommercial-NoDerivs 3.0 Unported License. The images or other third party material in this article are included in the article's Creative Commons license, unless indicated otherwise in the credit line; if the material is not included under the Creative Commons license, users will need to obtain permission from the license holder to reproduce the material. To view a copy of this license, visit http:// creativecommons.org/licenses/by-nc-nd/3.0/ 